\title{
PENGUJIAN PERFORMA DAN TINGKAT STRESS \\ PADA WEBSITE BAPENDA JAWA BARAT, JAWA TENGAH DAN JAWA TIMUR
}

\author{
Maria Christina \\ Sekolah Tinggi Manajemen Informatika dan Komputer LIKMI \\ Jl. Ir. Juanda 96 Bandung 40132 \\ e-mail : notden97@gmail.com
}

\begin{abstract}
ABSTRAK
Melayani masyarakat dengan menggunakan teknologi informasi dan komunikasi dengan menggunakan fasilitas website, memudahkan mayarakat dalam mencari informasi mengenai pajak dan bagaimana proses pembayaran pajak. Bapenda (Badan Pendapatan Daerah) merupakan suatu badan pemerintahan yang bertugas untuk menangani segala macam pendapatan daerah. Penerapan Bapenda dalam melayani kebutuhan masyarakat dalam memberikan informasi mengenai pajak adalah dengan meluncurkan sebuah website yang dapat diakses oleh mayarakat.

Bapenda Jawa Barat, Jawa Tengah dan Jawa Timur menjadi objek penelirian apakah website Bapenda dapat memenuhi kebutuhan masyarakat. Pengukuran kualitas ketiga website menggunakan webtool GTMetrix, WebPageTest, dan LoadImpact.com, dengan fokus load time dari ketiga website. Semakin kecil angka yang dihasilkan dari webtool, maka kinerja website semakin baik dan akan mempengaruhi minat masyarakat untuk menggunakannya.
\end{abstract}

Kata kunci : pelayanan, website, performa, kecepatan

\section{PENDAHULUAN}

Pembangunan suatu negara memerlukan dana atau pembiayaan yang sangat besar yang salah satunya bersumber dari pajak yang dibayarkan oleh penduduknya. Pajak daerah adalah pajak yang dipungut oleh suatu daerah berdasarkan peraturan pajak yang telah ditetapkan oleh daerah tersebut untuk kepentingan pembiayaan rumah tangganya sebagai bahan hokum public (Surantono,1997:57).

Penggunaan teknologi informasi dan komunikasi (TIK) yang berkembang sangat pesat dimanfaatkan oleh pemerintah daerah untuk memudahkan masyarakat dalam mencari informasi mengenai pajak dan proses pembayaran pajak. Salah satu penerapan penggunaan TIK dalam penyelenggaraan pelayanan pajak daerah adalah dengan diluncurkannya website Bapenda (Badan Pendapanan Daerah). Website ini diharapkan dapat meningkatkan pelayanan pubik yang lebih baik dan inovatif sehingga dapat mempercepat pertumbuhan dan pemerataan pembangunan daerah.

Penelitian ini menguji performa dan kecepatan server dalam menangani permintaan data dan juga menguji tingkat stress website untuk melihat apakah server dapat menangani beban kerja yang berat. Pengujian dilakukan pada 3 (tiga) website Bapenda di Pulau Jawa, yaitu Bapenda Jawa Barat (bapenda.jabarprov.go.id), Bapenda Jawa Tengah (bappeda.jatengprov.go.id) dan Bapenda Jawa Timur (bappeda.jatimprov.go.id).

Pengujian menggunakan webtool GTMetrix, WebPageTest, dan LoadImpact.com untuk melihat bagaiman ketiga server Bapenda dapat menangani beban yang diminta oleh penggunanya. 


\section{TUJUAN DAN MASALAH PENELITIAN}

a. Tujuan Penelitian

Tujuan penelitian ini adalah untuk mengukur kinerja dan kualitas 3 (tiga) website Bapenda dalam melayani masyarakat.

b. Batasan Masalah

Batasan masalah yang diambil dalam penelitian ini adalah mengukur performa dan kecepatan 3 (tiga) website Bapenda dengan menggunakan 3 buah webtool, yaitu GTMetrix, WebPageTest, dan LoadImpact.com.

\section{METODE PENELITIAN}

Objek obsevasi adalah 3 buah website Bapenda di Pulau Jawa dengan menguji performa dan kecepatan menggunakan metode webtool:

a. GTMetrix, untuk menguji kecepatan dan efisiensi dari website yang diuji dengan menggunakan google page speed dan Yahoo YSlow sebagai analyze engine dan untuk menampilkan hasil serta rekomendasi yang harus dilakukan. Poin akhir dari GTMetrix adalah A sampai F, dimana nilai A memiliki arti sangat bagus dan F bernilai sangat buruk. Untuk mendapatkan nilai A, hasil penilaian dari website harus diatas 90

b. WebPageTest.org, menguji kesalahan yang terjadi pada saat website dibuka oleh banyak orang di waktu yang bersamaan.

c. Loadimpact.com, menguji tingkat stress website dimana website yang diuji akan dilihat waktu respon, kecepatan transfer data, dan mengecek tingkat error yang terjadi pada saat penerimaan data.

Ketiga website yang akan diuji adalah website Bapenda Jawa Barat, Bapenda Jawa Tengah dan Bapenda Jawa Timur. Proses pengumpulan data terhadap ketiga webtool diatas dilakukan dengan menggunakan fasilitas komputer dan internet yang tersedia di rumah penguji, dengan kecepatan internet sebesar 8 Mbps.

\section{HASIL PENGUJIAN DAN PEMBAHASAN}

Berdasarkan hasil penelitian yang dilakukan pada July 2019 terhadap 3 website Bapenda di Pulau Jawa, berikut hasilnya :

a. GTMetrix

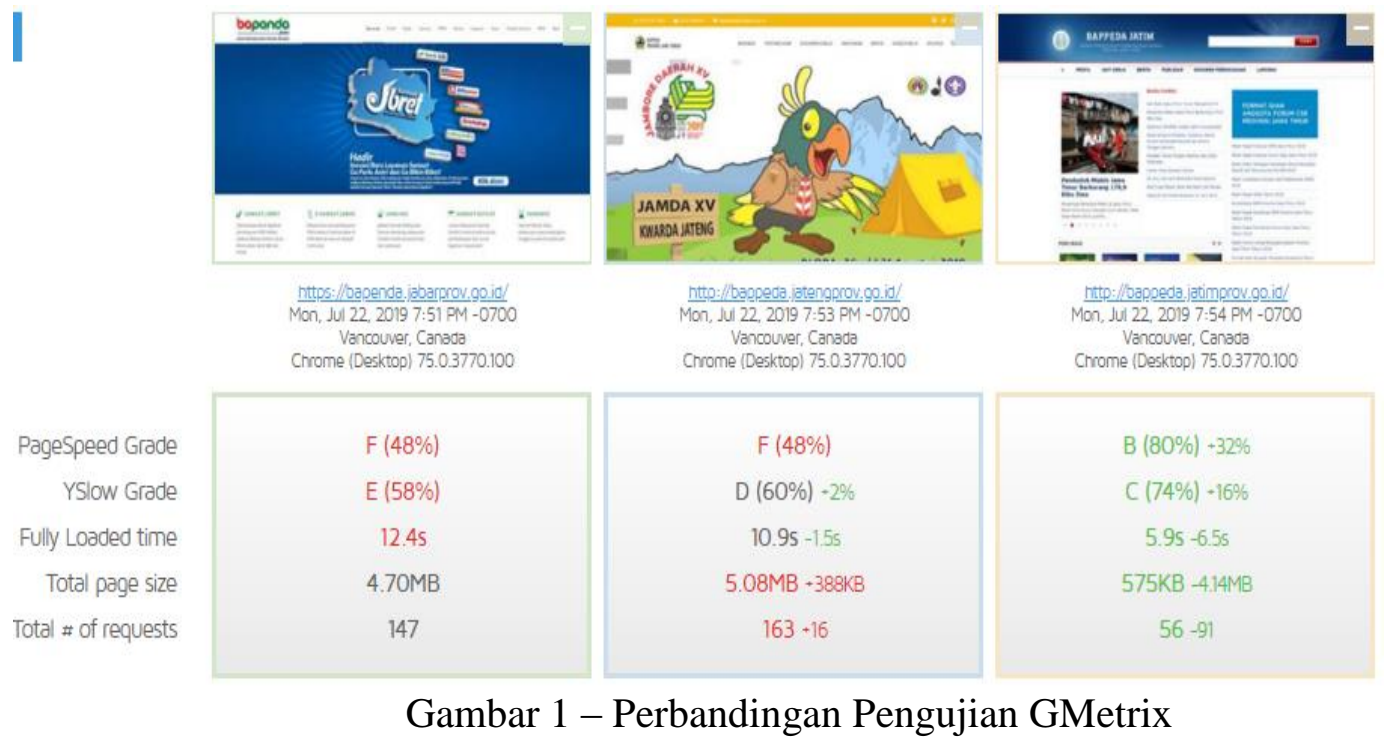


Berdasarkan hasil pengujian ketiga website, diperoleh hasil :

1) Dua website Bapenda yaitu Bapenda Jawa Barat dan Bapenda Jawa Tengah memperoleh hasil untuk Page Speed Grade di level F yang artinya kualitas kedua website masih sangat rendah dan Bapenda Jawa Timur di level B yang berarti website Bapenda Jawa Timur sudah Baik. Untuk kedua website yang bernilai $\mathrm{F}$, akan sangat berpengaruh terhadap kinerja website yang berakibat akan mempengaruhi masyarakat untuk menggunakan website tersebut untuk menggunakan fungsi yang ada.

2) Hal yang sama pun dihasilkan oleh pengujian dengan YSlow Grade, dimana rata-rata dari hasil pengujian tersebut adalah berada diangka $64 \%$ (D).

3) Salah satu faktor keberhasilan sebuah website adalah waktu tampil yang cepat (load time). Namun dari hasil pengujian, website Bapenda Jawa Barat dan Bapenda Jawa Tengah masih terbilang lama dengan waktu tampil sebesar 12.4 s dan 10.9 s. Sedangkan untuk website Bapenda Jawa Timur 6s yang bisa dikatakan baik (B). Waktu tampil yang lama tersebut disebabkan oleh besarnya ukuran halaman yang disebabkan banyaknya gambar berukuran besar. Oleh karena itu, perlu dipertimbangakan pada saat mendesain sebuah website apakah diperlukan gambar yang berukuran besar atau tidak, karena sangat mempengaruhi tingkat kecepatan waktu tampil sebuah website.

b. WebPage Test.org

Web Page Performance Test for bapenda.jabarprov.go.id

From: Jakarta, Indonesia - Chrome - Cable $23 / 7 / 201910.00 .57$

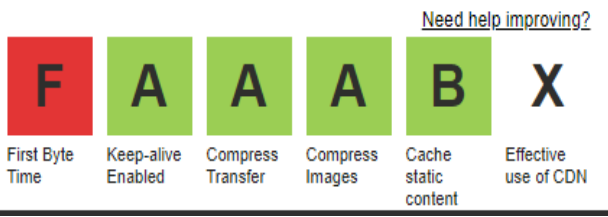

Performance Results (Median Run)

\begin{tabular}{|c|c|c|c|c|c|c|c|c|c|c|c|c|}
\hline & \multirow[b]{2}{*}{ Load Time } & \multirow[b]{2}{*}{ First Byte } & \multirow[b]{2}{*}{ Start Render } & \multirow[b]{2}{*}{ Speed Index } & \multirow[b]{2}{*}{$\underline{\text { Last Painted Hero }}$} & \multicolumn{3}{|c|}{ Document Complete } & \multicolumn{4}{|c|}{ Fully Loaded } \\
\hline & & & & & & Time & Requests & Bytes in & Time & Requests & Bytes In & Cost \\
\hline First View (Run 3) & $16.045 \mathrm{~s}$ & $2.983 \mathrm{~s}$ & $5.600 \mathrm{~s}$ & $11.271 \mathrm{~s}$ & $11.500 \mathrm{~s}$ & $16.045 \mathrm{~s}$ & 137 & $4,749 \mathrm{~KB}$ & $16.982 \mathrm{~s}$ & 146 & $4,781 \mathrm{~KB}$ & sSSSS \\
\hline
\end{tabular}

Gambar 2 - Hasil Pengujian Bapenda Jawa Barat

Web Page Performance Test for

bappeda.jatengprov.go.id

From: Jakarta, Indonesia - Chrome - Cable $23 / 7 / 201910.07 .02$

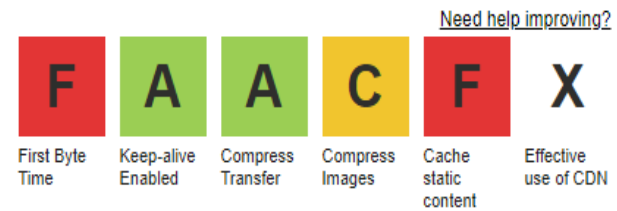

Performance Results (Median Run)

\begin{tabular}{|c|c|c|c|c|c|c|c|c|c|c|c|c|c|}
\hline & \multirow[b]{2}{*}{$\begin{array}{l}\text { Load } \\
\text { Time }\end{array}$} & \multirow[b]{2}{*}{$\begin{array}{l}\text { First } \\
\text { Byte }\end{array}$} & \multirow[b]{2}{*}{$\begin{array}{l}\text { Start } \\
\text { Render }\end{array}$} & \multirow[b]{2}{*}{$\begin{array}{l}\text { Speed } \\
\text { Index }\end{array}$} & \multirow[b]{2}{*}{$\frac{\text { Last Painted }}{\underline{\text { Hero }}}$} & \multirow[b]{2}{*}{$\frac{\text { First Interactive }}{\text { (beta) }}$} & \multicolumn{3}{|c|}{ Document Complete } & \multicolumn{4}{|c|}{ Fully Loaded } \\
\hline & & & & & & & Time & Requests & $\begin{array}{l}\text { Bytes } \\
\text { In }\end{array}$ & Time & Requests & $\begin{array}{l}\text { Bytes } \\
\text { In }\end{array}$ & Cost \\
\hline $\begin{array}{l}\text { First View } \\
\text { (Run 3) }\end{array}$ & $10.047 \mathrm{~s}$ & $1.365 \mathrm{~s}$ & $4.300 \mathrm{~s}$ & $10.651 \mathrm{~s}$ & $11.000 \mathrm{~s}$ & $>9.740 \mathrm{~s}$ & $10.047 \mathrm{~s}$ & 136 & $\begin{array}{c}4,649 \\
\mathrm{~KB}\end{array}$ & $11.290 \mathrm{~s}$ & 161 & $\begin{array}{l}5,150 \\
K B\end{array}$ & SSSSS \\
\hline
\end{tabular}

Gambar 3 - Hasil Pengujian Bapenda Jawa Tengah 
Web Page Performance Test for

bappeda.jatimprov.go.id

From: Jakarta, Indonesia - Chrome - Cable $237 / 201910.20 .36$

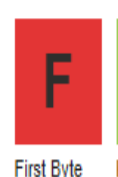

First Byte Keep-alive Compress Compress Time Enabled Transfer Images

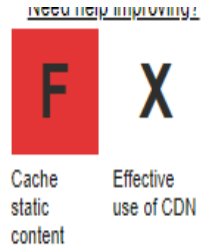

Performance Results (Median Run)

\begin{tabular}{|c|c|c|c|c|c|c|c|c|c|c|c|c|c|}
\hline & & & & & & & \multicolumn{3}{|c|}{ Document Complete } & \multicolumn{4}{|c|}{ Fully Loaded } \\
\hline & $\begin{array}{l}\text { Load } \\
\text { Time }\end{array}$ & $\begin{array}{l}\text { First } \\
\text { Byte }\end{array}$ & $\begin{array}{l}\text { Start } \\
\text { Render }\end{array}$ & $\begin{array}{l}\text { Speed } \\
\text { Index }\end{array}$ & $\frac{\text { Last Painted }}{\underline{\text { Hero }}}$ & $\frac{\text { First Interactive }}{\text { (beta). }}$ & Time & Requests & $\begin{array}{l}\text { Bytes } \\
\text { In }\end{array}$ & Time & Requests & $\begin{array}{l}\text { Bytes } \\
\text { In }\end{array}$ & Cost \\
\hline $\begin{array}{c}\text { First View } \\
\text { (Run 2) }\end{array}$ & $2.384 \mathrm{~s}$ & $0.749 \mathrm{~s}$ & $1.300 \mathrm{~s}$ & $1.512 \mathrm{~s}$ & $1.400 \mathrm{~s}$ & $>1.302 \mathrm{~s}$ & $2.384 \mathrm{~s}$ & 57 & $\begin{array}{l}560 \\
\text { KB }\end{array}$ & $2.452 \mathrm{~s}$ & 58 & $\begin{array}{l}561 \\
K B\end{array}$ & $\$ S-=$ \\
\hline
\end{tabular}

Gambar 4 - Hasil Pengujian Bapenda Jawa Timur

Tabel 1 - Perbandingan Keseluruhan Website

\begin{tabular}{|c|c|c|c|c|}
\hline & & $\begin{array}{l}\text { Jawa } \\
\text { Barat }\end{array}$ & $\begin{array}{c}\text { Jawa } \\
\text { Tengah }\end{array}$ & $\begin{array}{c}\text { Jawa } \\
\text { Timur }\end{array}$ \\
\hline \multicolumn{2}{|l|}{ Load Time } & $16.45 \mathrm{~s}$ & $10.047 \mathrm{~s}$ & $2.384 \mathrm{~s}$ \\
\hline \multicolumn{2}{|l|}{ First Byte } & $2.983 \mathrm{~s}$ & $1.365 \mathrm{~s}$ & $0.749 \mathrm{~s}$ \\
\hline \multicolumn{2}{|c|}{ Start Render } & $5.600 \mathrm{~s}$ & $4.300 \mathrm{~s}$ & $1.300 \mathrm{~s}$ \\
\hline \multicolumn{2}{|c|}{ Speed Index } & $11.27 \mathrm{~s}$ & $10.651 \mathrm{~s}$ & $1.512 \mathrm{~s}$ \\
\hline \multicolumn{2}{|c|}{ Last Painted Hero } & $11.500 \mathrm{~s}$ & $11.000 \mathrm{~s}$ & $1.400 \mathrm{~s}$ \\
\hline \multicolumn{2}{|c|}{ First Interactive } & \#NA\# & $>9.740 \mathrm{~s}$ & $>1.302 \mathrm{~s}$ \\
\hline \multirow{3}{*}{$\begin{array}{l}\text { Document } \\
\text { Complete }\end{array}$} & Time & $16.45 \mathrm{~s}$ & $10.047 \mathrm{~s}$ & $2.384 \mathrm{~s}$ \\
\hline & Request & 137 & 136 & 57 \\
\hline & Bytes in & $4.749 \mathrm{~KB}$ & $4.649 \mathrm{~KB}$ & $560 \mathrm{~KB}$ \\
\hline \multirow{4}{*}{$\begin{array}{c}\text { Fully } \\
\text { Loaded }\end{array}$} & Time & $16.982 \mathrm{~s}$ & $11.290 \mathrm{~s}$ & $2.452 \mathrm{~s}$ \\
\hline & Requests & 146 & 161 & 56 \\
\hline & Bytes in & $4.781 \mathrm{~KB}$ & $5.150 \mathrm{~KB}$ & $561 \mathrm{~KB}$ \\
\hline & Cost & $\$ \$ \$$ & $\$ \$ \$$ & $\$ \$ \$$ \\
\hline
\end{tabular}

Load Time pada tabel 1 merupakan waktu tampil website dari mulai tampilnya halaman, First Byte adalah waktu yang dihasilkan dari awal meminta tampilan website sampai munculnya byte pertama dalam website. Start Render adalah kecepatan waktu untuk memunculkan tampilan awal website dalam bentuk angka indeks, dimana jika nilai yang ditampilkan semakin kecil maka akan lebih baik.

Berdasarkan hasil pada tabel 1 diatas dapat disimpulkan bahwa :

1) Bapenda Jawa Barat memiliki nilai tertinggi untuk hampir setiap pengukuran, sehingga dapat disimpulkan bahwa website Bapenda Jawa Barat masih memerlukan perbaikan website. Namun nilai untuk kompresi image dan cache static content sangat baik, ini menandakan bahwa webstite Bapenda Jawa Barat sudah memikirkan kebutuhan tersebut, tetapi masih belum maksimal. Selain itu salah satu factor Bapenda Jawa Barat memiliki nilai yang kurang baik karena fitur yang ada didalamnya lebih lengkap dibandingkan dengan 2 Bapenda yang lain. 
2) Bapenda Jawa Timur memiliki nilai yang baik di setiap pengukurannya, hal ini disebabkan karena isi dari website masih bersifat informasi dan jumlah halaman website masih sedikit.

3) Bapenda Jawa Barat memiliki ukuran dokumen yang paling besar jika dibandingkan dengan Bapenda lainnya yaitu sebesar 4.749 KB, angka tersebut berbanding lurus dengan load time yaitu sebesar 16.982 s. Namun untuk Bapenda Jawa Tengah yang memiliki ukuran dokumen yang hampir sama dengan Bapenda Jawa Barat, angka load time berbeda 5 detik.

4) Pada bagian Fully Loaded yang merupakan waktu yang diperlukan untuk menampilkan keseluruhan website, Bapenda Jawa Timur memiliki waktu yang paling kecil dibandingkan dengan Bapenda yang lainnya. Hal yang sama berlaku untuk pengukuran lainnya.

\section{c. Loadimpact.com}

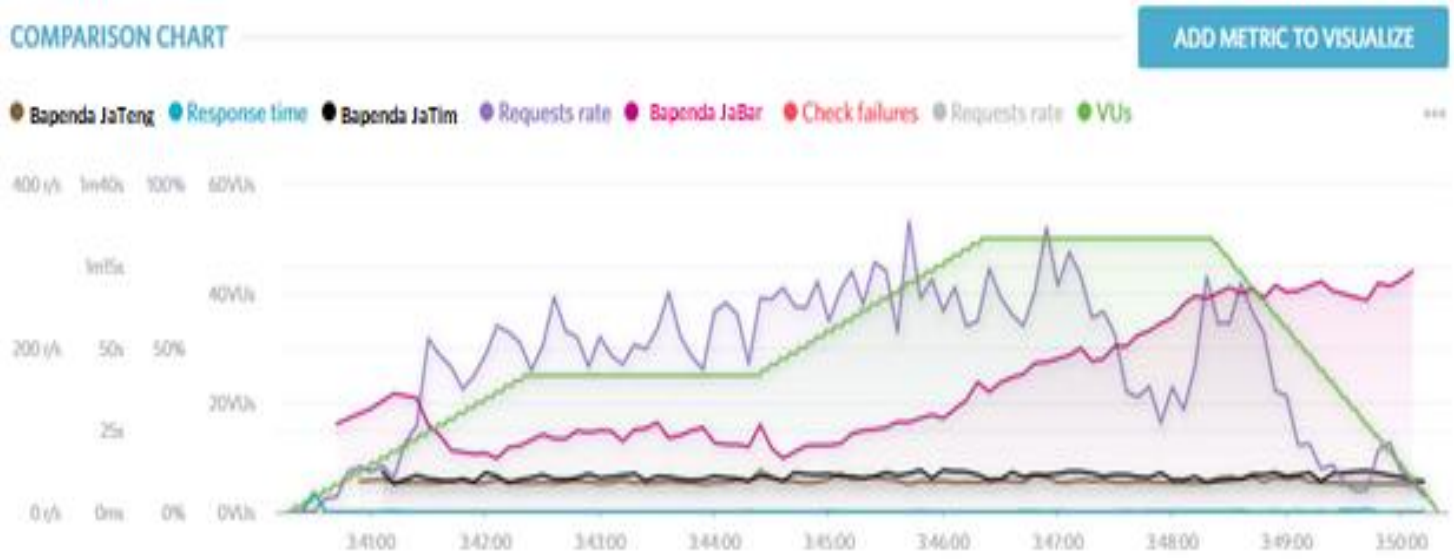

Gambar 5 - Pengujian Stressing Website

Menggunakan $50 \mathrm{VU}$ (virtual user) untuk menguji website apakah mampu untuk menangani permintaan secara langsung dengan jumlah pengguna yang banyak diwaktu yang bersamaan. Gambar 5 diatas menunjukkan bahwa Bapenda Jawa Tengah dan Bapenda Jawa Timur memiliki respon waktu yang tidak jauh berbeda untuk banyaknya VU yang mengakses di waktu yang bersamaan. Sedangkan Bapenda Jawa Barat jauh diatas kedua Bapenda, terlebih dapat dilihat pada saat $50 \mathrm{VU}$ yang mengakses secara bersamaan. Hal tersebut menunjukkan bahwa semakin tinggi grafik yang dihasilkan, maka waktu yang diperlukan untuk menampilkan website akan semakin lama.

\section{KESIMPULAN}

Ketiga hal yang diuji dalam penelitian ini merupakan hal yang penting untuk menilai apakah sebuah website berkualitas. Penelitian menggunakan 3 alat uji berbasis webtools, yaitu GTMatrix, WebPageTest.org dan LoadImpact.com. Berdasarkan ketiga alat uji tersebut bahwa kualitas website Bapenda masih belum memuaskan, terutama Bapenda Jawa Barat. Kualitas sebuah website sangat berpengaruh terhadap minat pengguna untuk menggunakan fasilitas yang ada di dalam website tersebut, yang dapat dilihat dari load time yang dihasilkan dengan rata-rata $9.627 \mathrm{~s}$.

Untuk website Bapenda Jawa Barat, saran yang dapat diberikan berdasarkan hasil pengujian diatas adalah meningkatkan kinerja website Bapenda Jawa Barat terlebih difokuskan pada load time website, sehingga dapat memberikan kenyamanan dan minat pengguna yang akhirnya dapat memberikan informasi yang cepat kepada masyarakat. 


\section{DAFTAR PUSTAKA}

[1] Sommervile, I. (2011). Software Engineering Ninth Edition. Addison-Wesley.

[2] Sugiyono. 2010. Metode Penelitian Pendidikan : Pendekatan Kuantitatif, Kualitatif, dan R\&D. Alfabeta. Bandung.

[3] Arikunto, S. 2010. Prosedur Penelitian Suatu Pendekatan Praktik. Rineka Cipta. Yogyakarta.

[4] Masyhur, Firdaus. (2014). Jurnal Kinerja Website Resmi Pemerintah Provinsi di Indonesia. Makassar

[5] Fitri, Sulidar. (2017). Junal Pengujian Kinerja Website dan Analisis Deskriptif Kualitas Website Pada Situr Universitas. Tasikmalaya

[6] Putra, C. A. (2013). Megukur Kecepatan dan Kualitas Website dengan GTMetrix. Diambil dari www.candra.web.id

[7] Test Run https://GTMetrix.com/ diuji 25 Juni 2019

[8] Test Run https://www.webpagetest.org/testlog/1/ diuji 25 Juni 2019

[9] Test Run https://app.loadimpact.com/ diuji 25 Juni 2019 